\title{
Re-emergent tremor in a patient with Parkinson's disease
}

\author{
Kazuyuki Noda, ${ }^{1}$ Nobutaka Hattori, ${ }^{2}$ Yasuyuki Okuma ${ }^{1}$
}

${ }^{1}$ Department of Neurology, Juntendo Shizuoka Hospital, Izunokuni, Shizuoka, Japan ${ }^{2}$ Department of Neurology, Juntendo University School of Medicine, Tokyo, Japan

\section{Correspondence to} Dr Kazuyuki Noda,

k-noda@juntendo.ac.jp

Accepted 21 July 2016

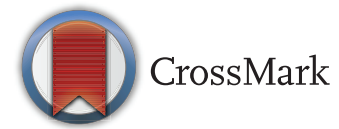

To cite: Noda K, Hattori N, Okuma Y. BMJ Case Rep Published online: [please include Day Month Year] doi:10.1136/bcr-2016216436

\section{DESCRIPTION}

A 62-year-old woman had a 3-year history of left leg resting tremor. The tremor was initially present when she was sitting. Two years later, she also developed resting tremor of her left hand. Her hand tremor is slow $(4-6 \mathrm{~Hz})$, involving the thumb, fingers or wrist. The tremor is also present when she was maintaining a posture (eg, outstretched hand) with a delayed onset of 2-4 s, called 're-emergent tremor' (score of 35 in the Movement Disorders Society-Unified Parkinson's Disease Rating Scale (MDS-UPDRS part III)), video 1). Her family history was negative for neurological disorders. Brain MRI findings were normal. The uptake of ${ }^{123}$ I-ioflupane single-photon emission CT was significantly reduced in both putamina with an asymmetrical pattern (right $>$ left) (figure 1). She was diagnosed as having Parkinson's disease (PD)

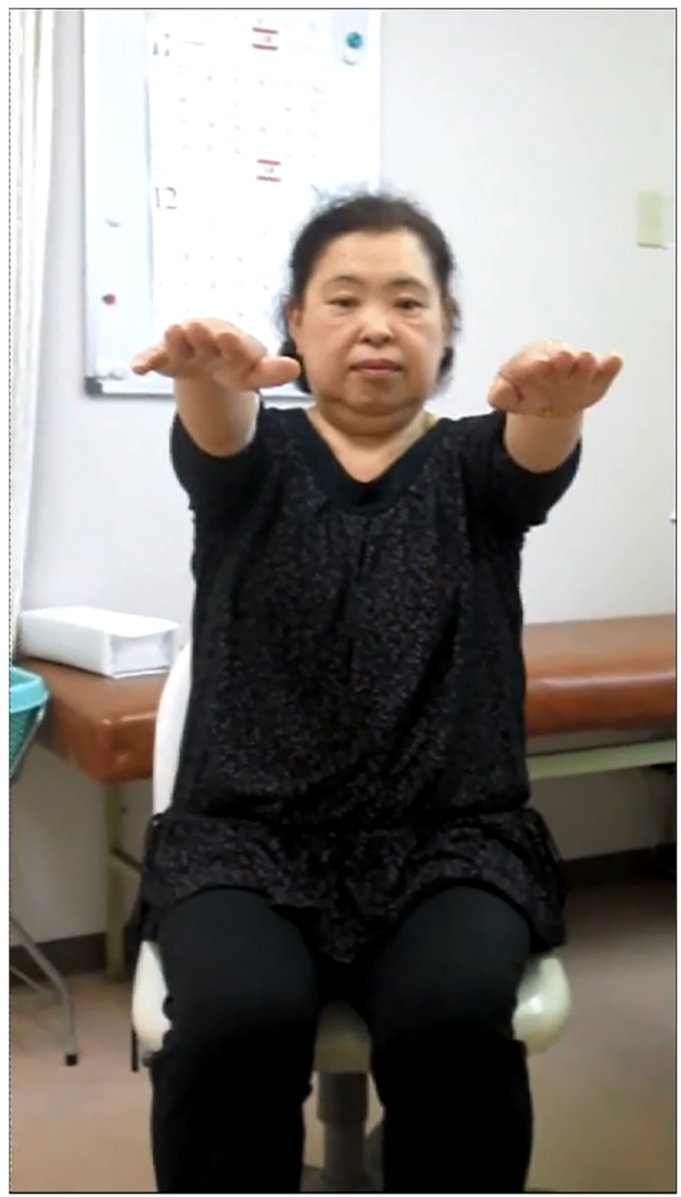

Video 1 This is a 62-year-old woman with a 3-year history of predominantly left hand tremor. The tremor is present when she is in a sitting position, and she is also bothered by the re-emergent tremor when she maintains an outstretched posture.

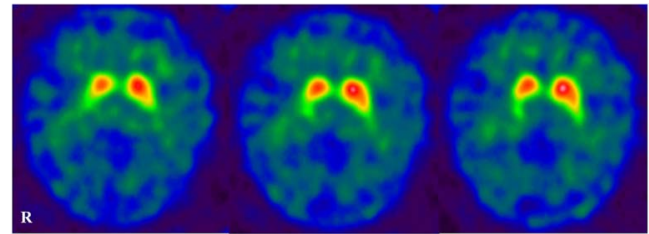

Figure $1{ }^{123}$ I-ioflupane single-photon emission CT scan showing asymmetrical reduction of tracer uptake in both putamina (right>left).

and started on $250 \mathrm{mg}$ of levodopa/benserazide per day. She still reported that her left hand was still shaking, thus, medications were titrated to levodopa/benserazide $450 \mathrm{mg} /$ day, entacapone $300 \mathrm{mg} /$ day, amantadine $150 \mathrm{mg} /$ day and zonisamide $50 \mathrm{mg} /$ day. Her bradykinesia, resting tremor and postural tremor improved (score of 14 on MDS-UPDRS part III, video 2).

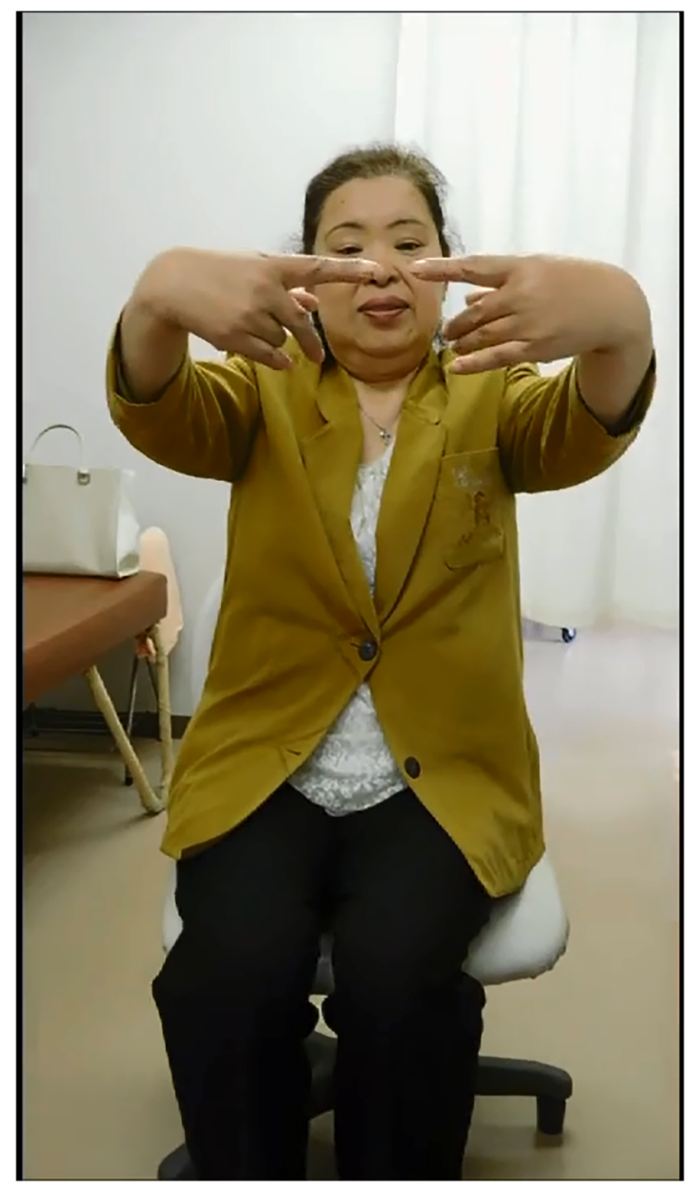

Video 2 The patient resting and re-emergent tremors were markedly improved by treatment with dopaminergic agents. 
Resting tremor is a cardinal feature of PD, but other types of tremor including postural and kinetic tremors may also occur. In people with parkinsonism, postural tremor emerges after a variable latency $(1-47$, mean $=9.4)$ in seconds with a frequency typical of parkinsonian tremor $(4-7 \mathrm{~Hz}){ }^{1}$ Jankovic et al ${ }^{1}$

\section{Learning points}

- Although resting tremor is a typical form of tremor associated with Parkinson's disease, people with parkinsonism may also develop postural tremor.

- In people with parkinsonism, postural tremor appears after a latency while maintaining a posture, which is termed re-emergent tremor.

- Re-emergent tremor has a similar frequency to typical resting tremor and may respond well to dopaminergic therapy. defined it as re-emergent tremor. Postural tremor of PD can be misdiagnosed as essential tremor (ET). ${ }^{2}$ The differential diagnosis of PD from ET in our patient was however, not difficult because of the presence of clearly observable resting tremor. This re-emergence is a key feature that helps differentiate PD from ET. Early recognition of re-emergent tremor and treatment are required.

Contributors $\mathrm{KN}$ cared for the patient in the outpatient settings. $\mathrm{NH}$ and $\mathrm{YO}$ reviewed the manuscript and provided suggestions. All the authors contributed to the writing of the manuscript, and read and approved the final version of the manuscript.

Competing interests None declared.

Patient consent Obtained.

Provenance and peer review Not commissioned; externally peer reviewed.

\section{REFERENCES}

1 Jankovic J, Schwartz KS, Ondo W. Re-emergent tremor of Parkinson's disease. J Neurol Neurosurg Psychiatr 1999;67:646-50.

2 Jankovic J. How do I examine for re-emergent tremor? Mov Disord Clin Pract 2016; doi:10.1002/mdc3.12329

Copyright 2016 BMJ Publishing Group. All rights reserved. For permission to reuse any of this content visit

http://group.bmj.com/group/rights-licensing/permissions.

BMJ Case Report Fellows may re-use this article for personal use and teaching without any further permission.

Become a Fellow of BMJ Case Reports today and you can:

- Submit as many cases as you like

- Enjoy fast sympathetic peer review and rapid publication of accepted articles

- Access all the published articles

- Re-use any of the published material for personal use and teaching without further permission

For information on Institutional Fellowships contact consortiasales@bmjgroup.com

Visit casereports.bmj.com for more articles like this and to become a Fellow 